\title{
Thiol-activatable triplet-triplet annihilation upconversion with maleimide-perylene as the caged triplet acceptor/emitter
}

\author{
Zafar Mahmood ${ }^{a}$ and Jianzhang Zhao ${ }^{a, *}$ \\ ${ }^{a}$ State Key Laboratory of Fine Chemicals, School of Chemical Engineering, Dalian \\ University of Technology, E-208 West Campus, 2 Ling-Gong Road, \\ Dalian 116024, P. R. China \\ E-mail: zhaojzh@dlut.edu.cn ～Web: http://finechem2.dlut.edu.cn/photochem
}

\section{Contents}

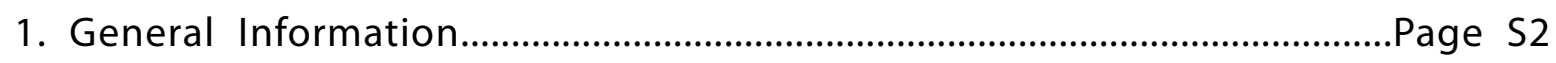

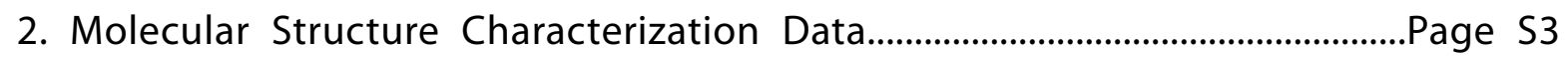

3. Changes in UV/ Visible Absorption Spectra With RSH......................................Page S10

4. Changes in fluorescence emission spectra With RSH................................................Page S11

5. Structure confirmation by HRMS analysis of Reaction mixture..............................Page S12

6. Changes in Fluorescence lifetime with RSH.............................................................Page S14

7. Switching of TTA Upconversion with RSH............................................................Page S15

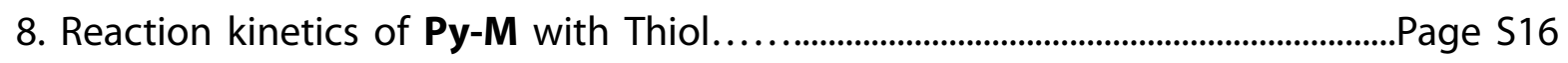

9. Calculation of charge transfer Quantum yield.........................................................Page S17

10. Nanosecond Time-resolved Difference Absorption Spectra.....................................Page S18

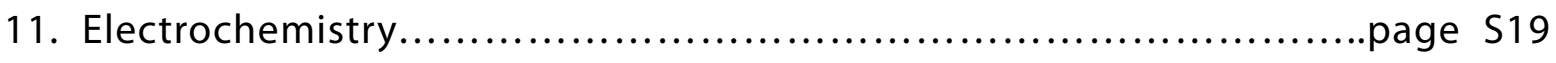

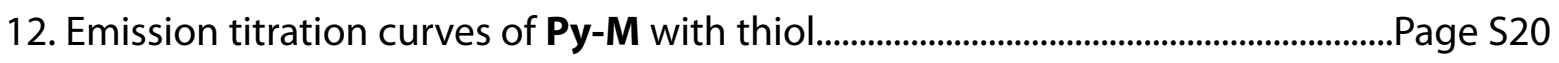




\section{General information}

All the chemicals used in synthesis are analytical pure and were used as received. Solvents were dried and distilled before used for synthesis. 


\section{Molecular structure characterization data}

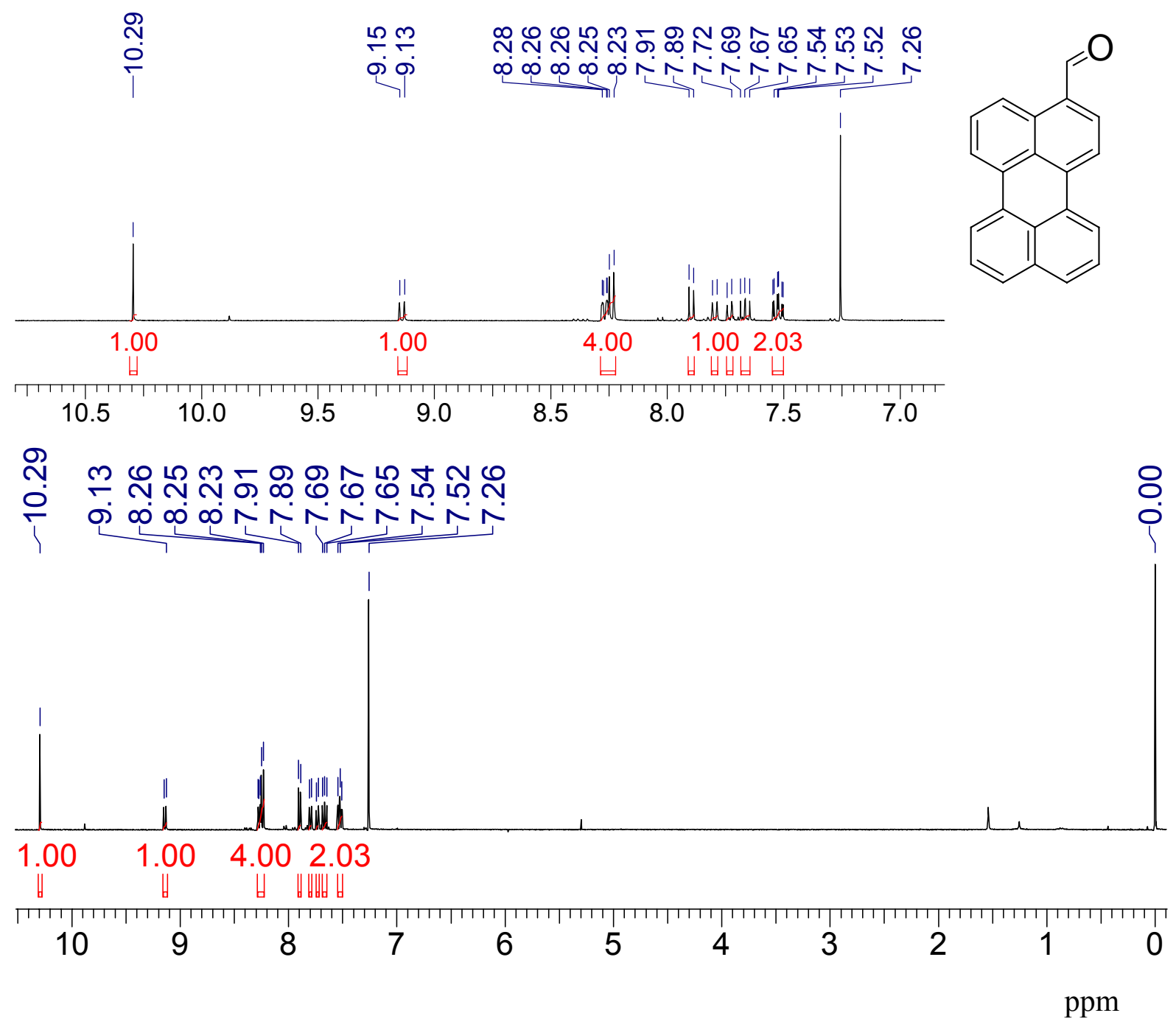

Figure S1. 'H NMR spectra of compound $1\left(400 \mathrm{MHz}, \mathrm{CDCl}_{3}\right)$. 
zjz150727-4 355 (5.918) Cm (353:382-126:194)
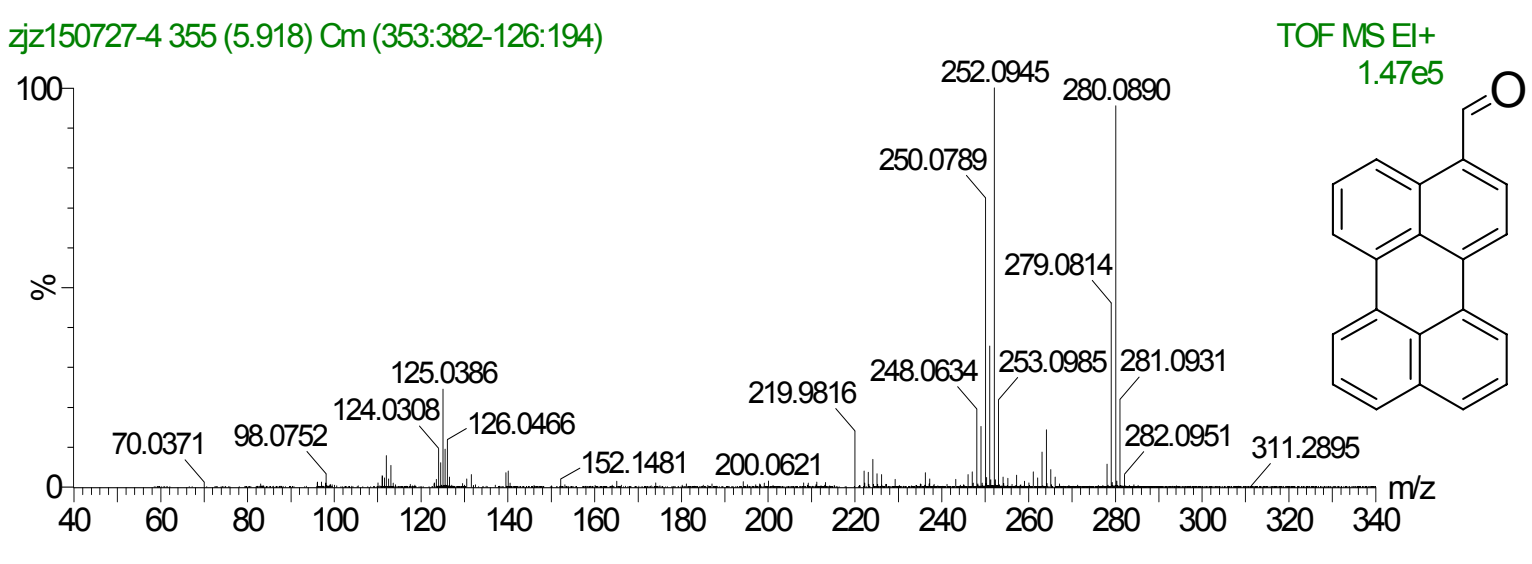

Figure S2. TOF MS El+ of compound 1.

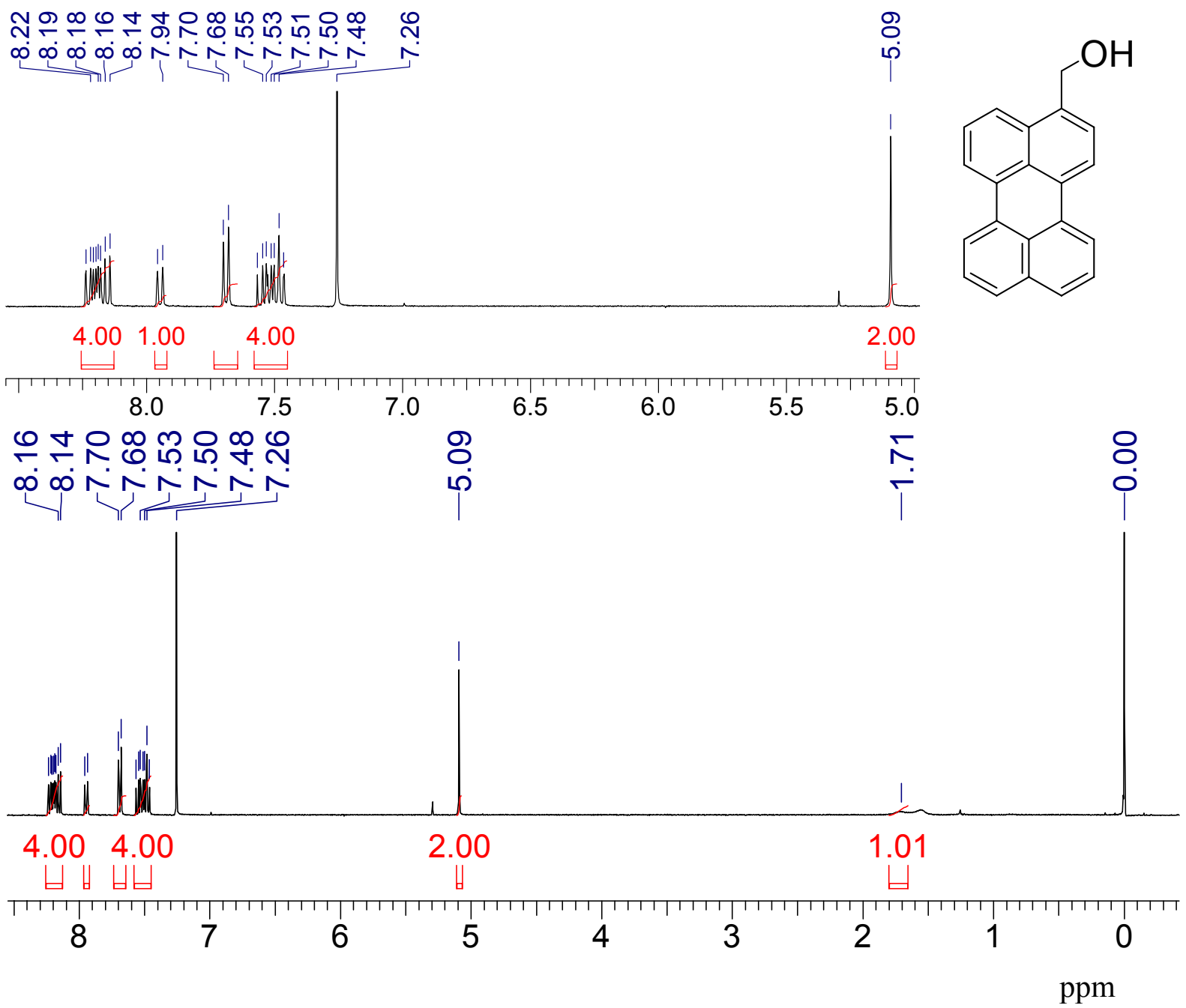

Figure S3. ${ }^{1} \mathrm{H}$ NMR spectra of compound $2\left(400 \mathrm{MHz}, \mathrm{CDCl}_{3}\right)$. 


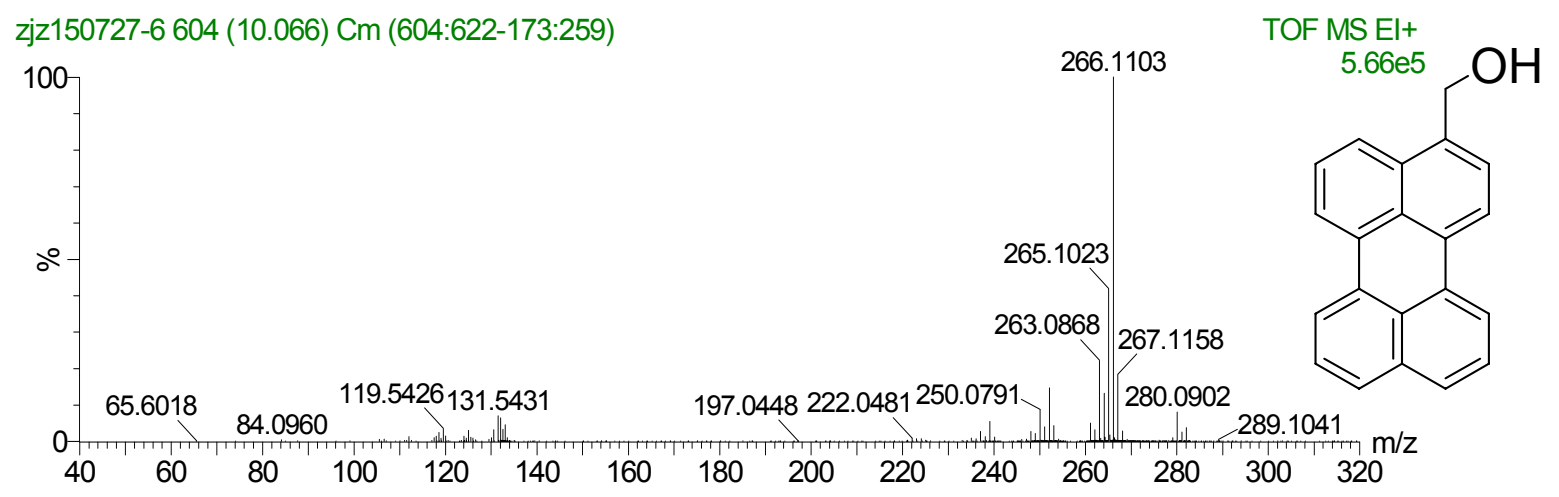

Figure S4. TOF MS El+ of compound 2.

윢

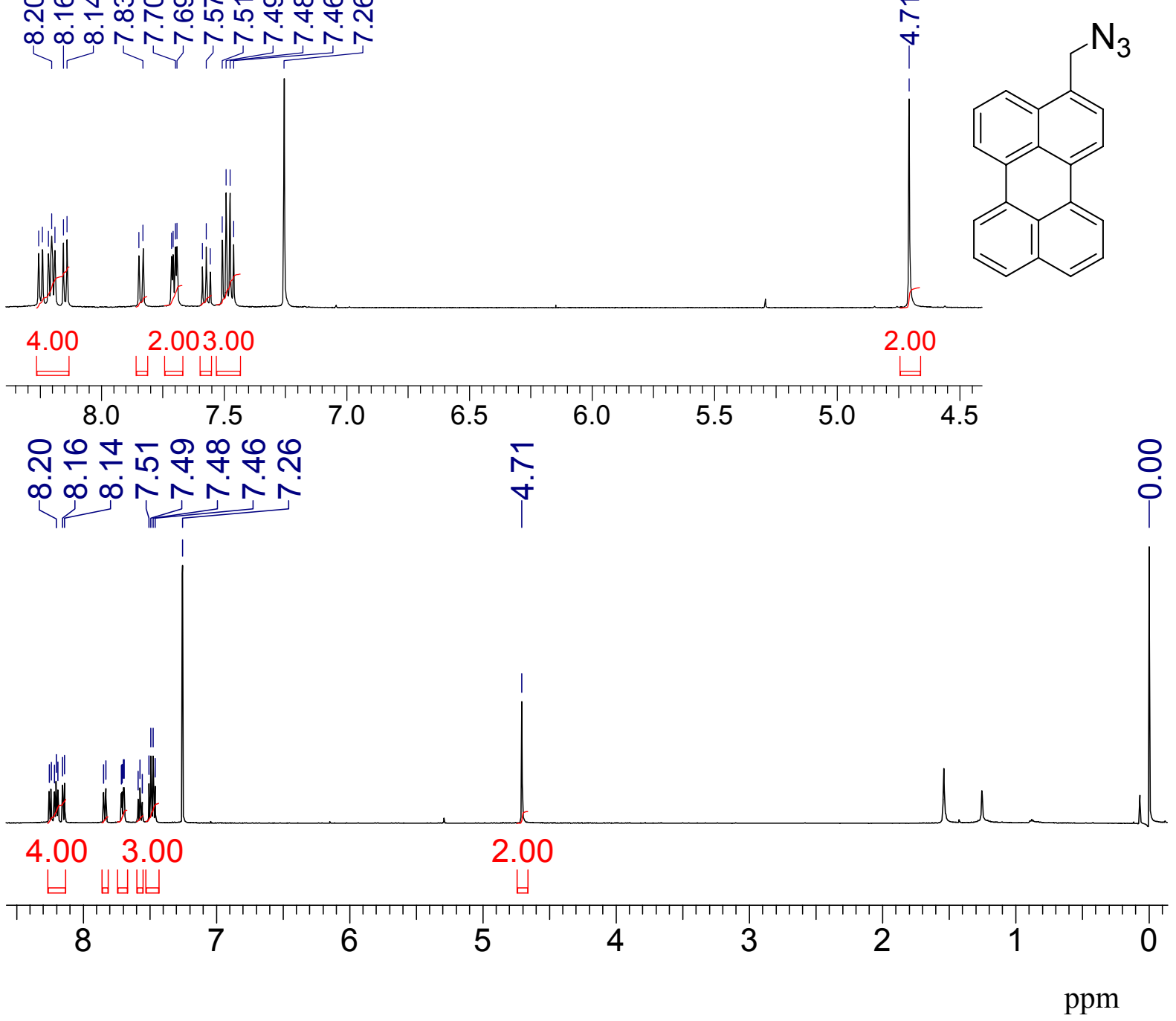

Figure S5. 'H NMR spectra of compound $3\left(400 \mathrm{MHz}, \mathrm{CDCl}_{3}\right)$. 


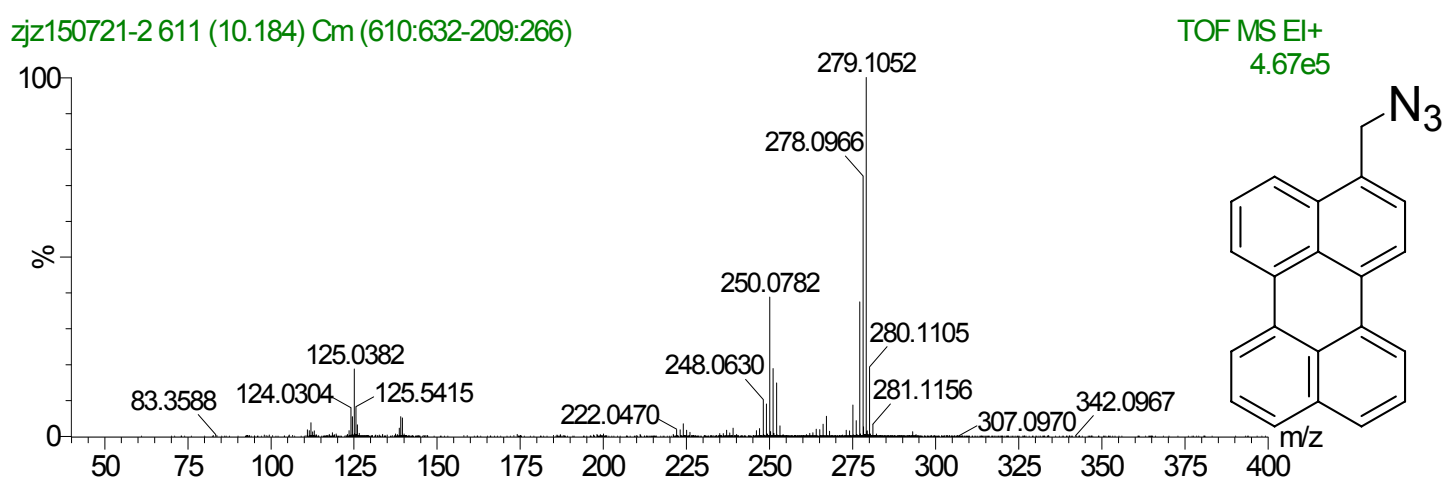

Figure S6. TOF MS El+ of compound 3.

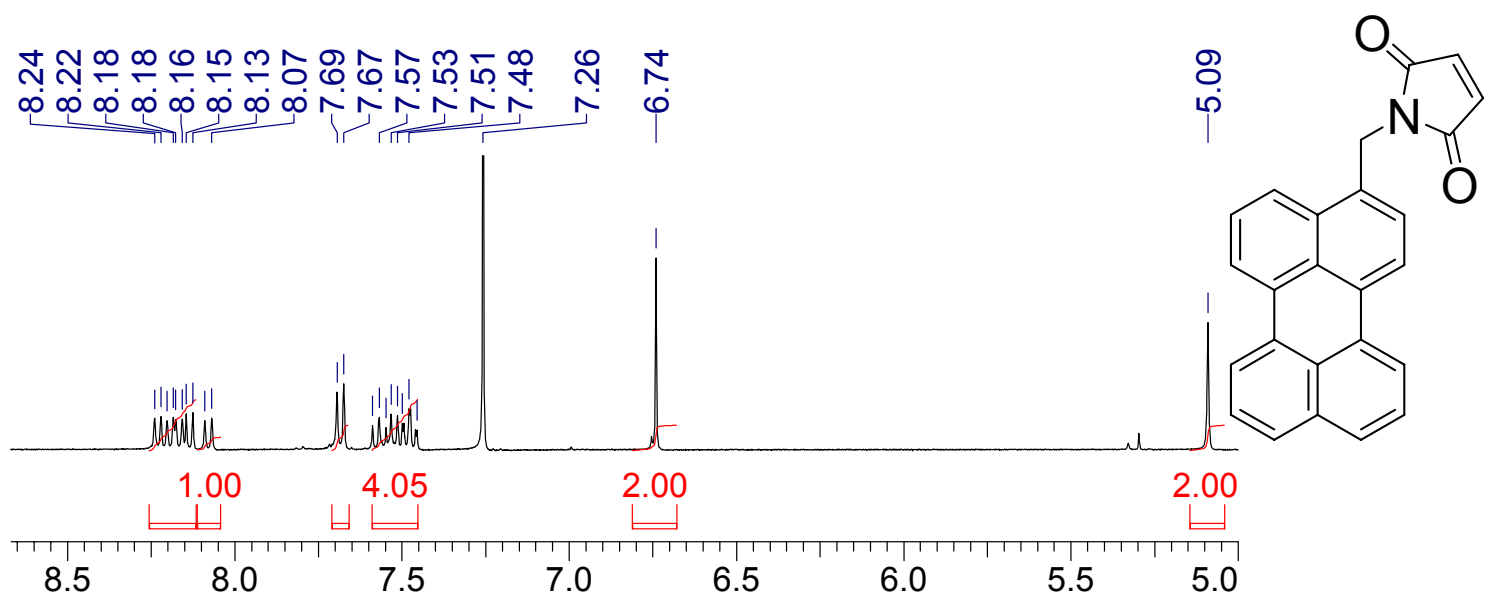

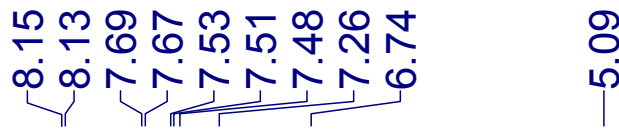

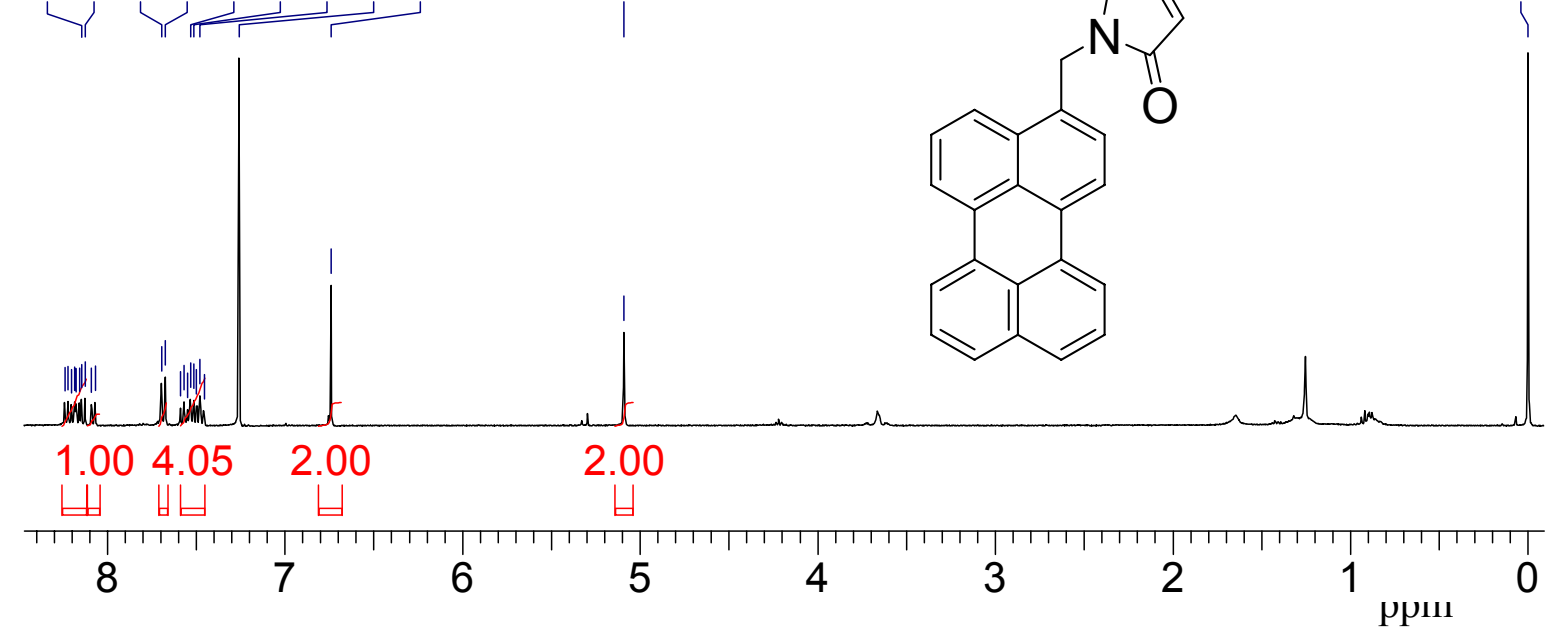

Figure S7. ' $\mathrm{H}$ NMR spectra of compound Py-M (500 MHz, $\left.\mathrm{CDCl}_{3}\right)$. 
ZJZ150605-1 480 (8.000) Om (480:503-188:239)

100

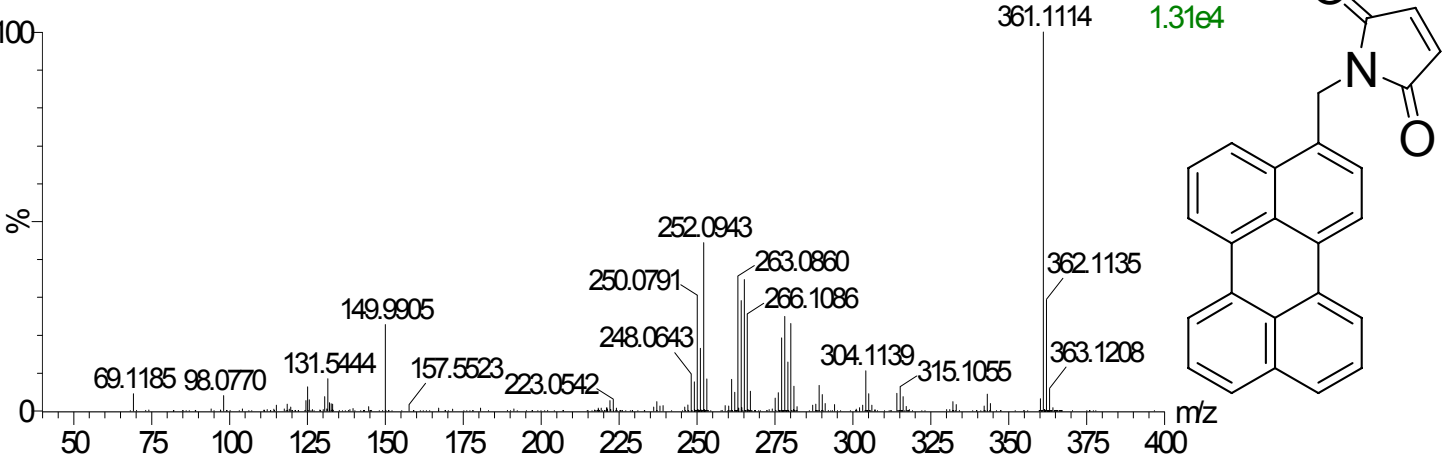

Figure S8. TOF MS El+ of compound Py-M.

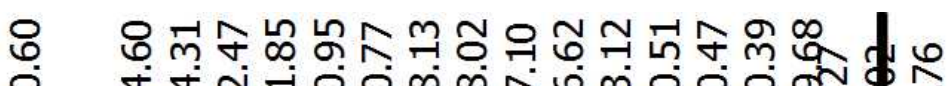

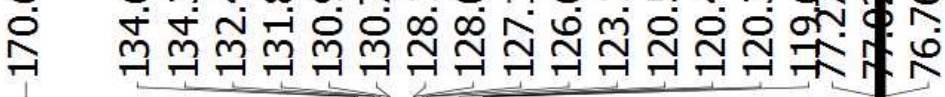

$\mathscr{\wp}$

लें

8.<smiles>CCCCN1C(=O)C=CC1=O</smiles>

ppm

Figure S9. ${ }^{13} \mathrm{C}$ NMR of compound $\mathbf{P y}-\mathbf{M}$ in $\mathrm{CDCl} 3(100 \mathrm{MHz}), 25^{\circ} \mathrm{C}$. 


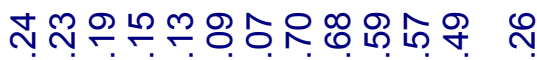

$\infty \infty \infty \infty \infty \infty \infty N N N$

政
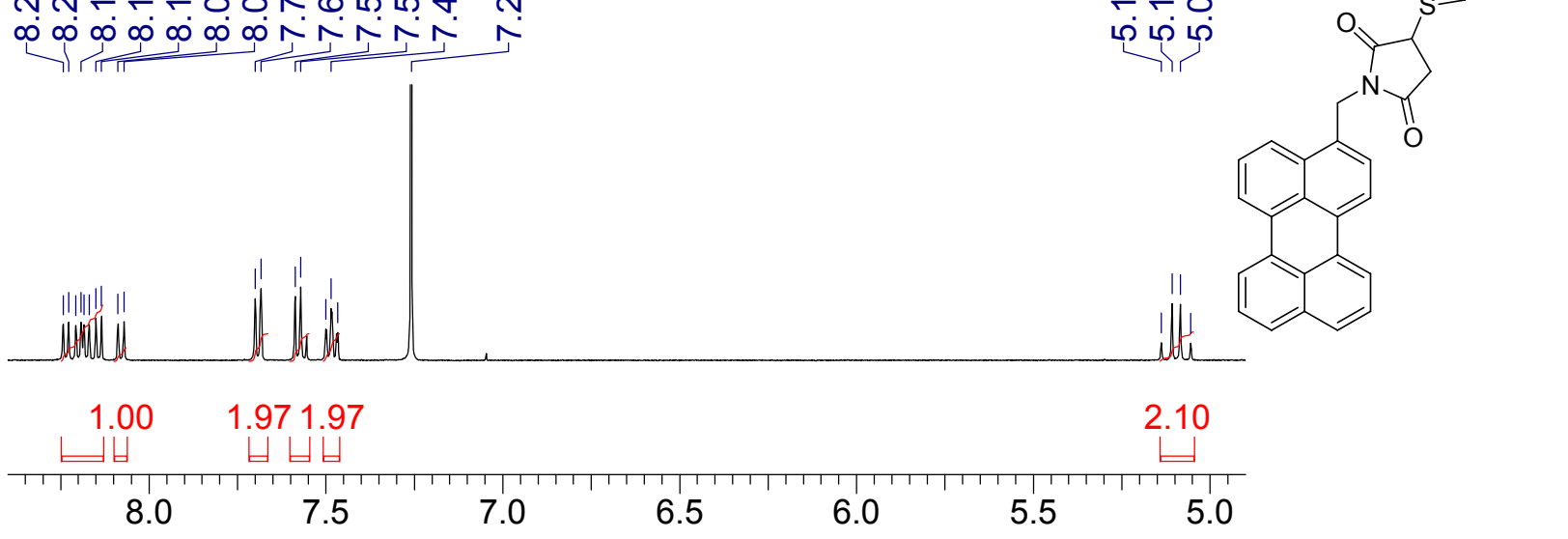

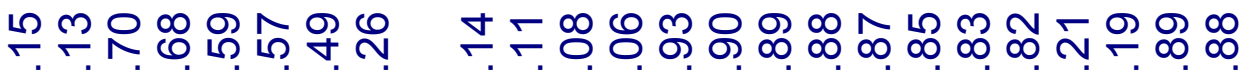

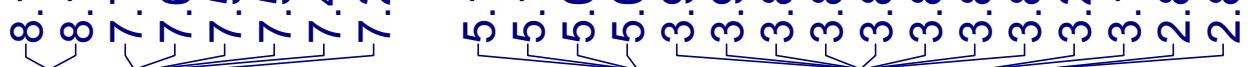

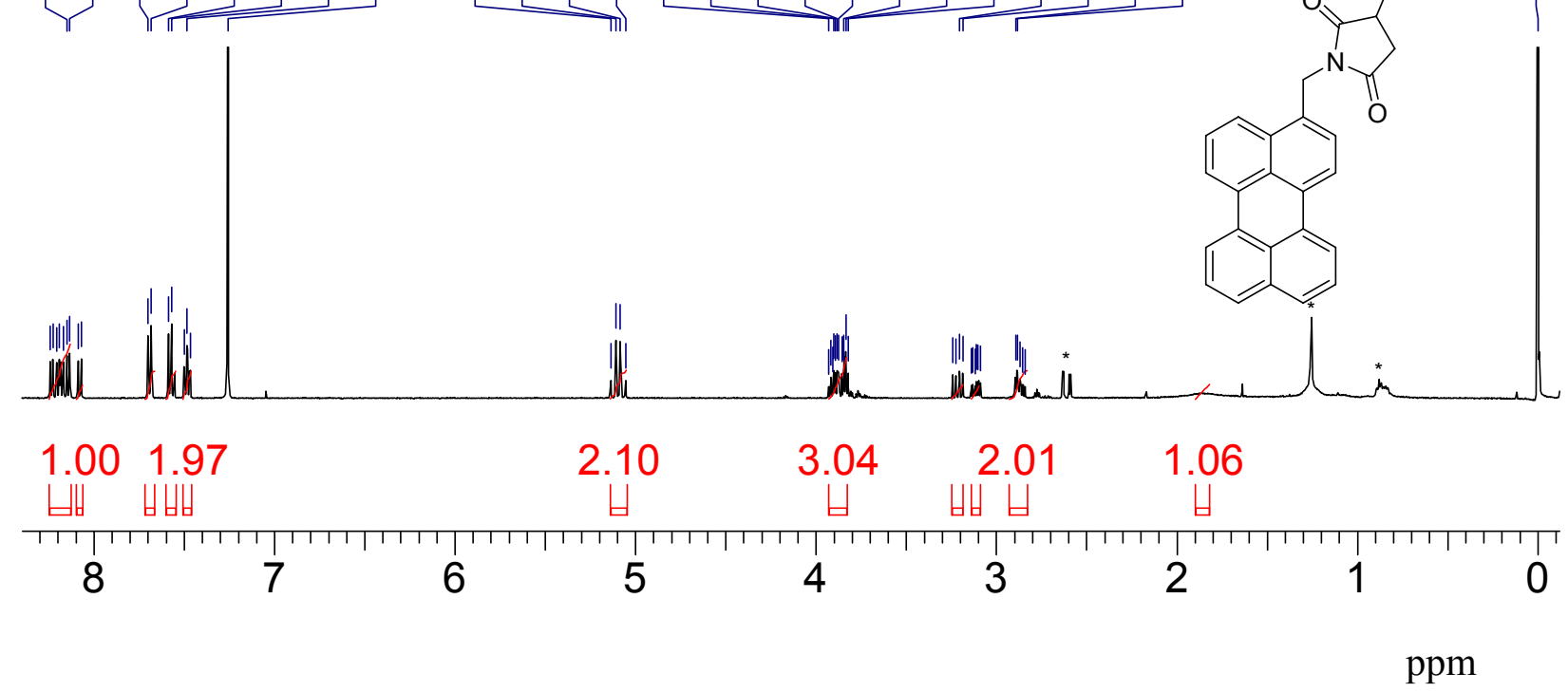

Figure S10. ' $\mathrm{H}$ NMR spectra of compound Py-M-adduct $\left(500 \mathrm{MHz}, \mathrm{CDCl}_{3}\right)$. 


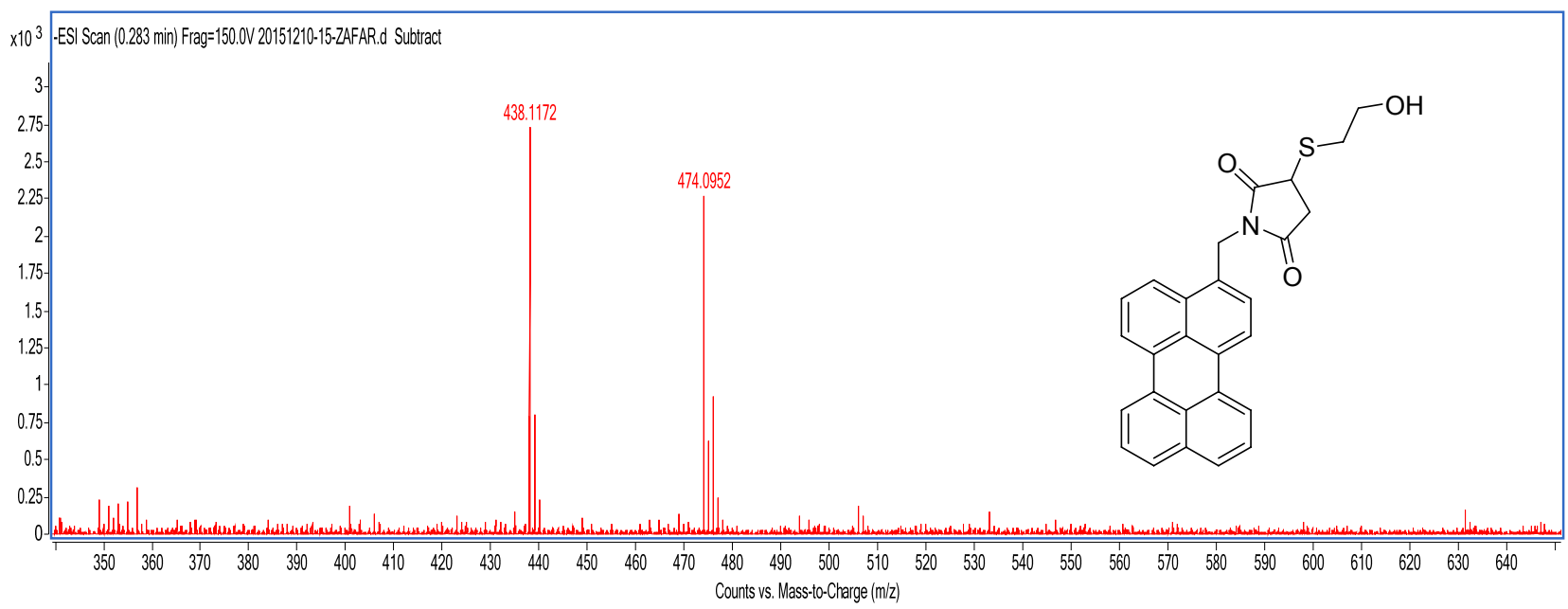

Figure S11. TOF HRMS ESI of compound Py-M adduct. 


\section{Changes in UV-visible absorption spectra with RSH.}

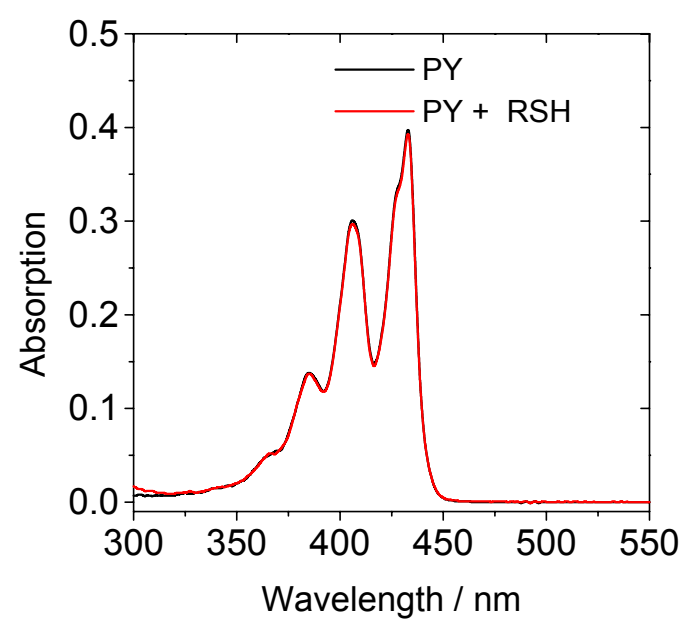

Figure S12. UV-visible absorption spectra of Py and Py +200 equiv 2-mercaptoethanol (RSH) $. c=1.0 \times 10^{-5} \mathrm{M}$ in Methanol, $20^{\circ} \mathrm{C}$.
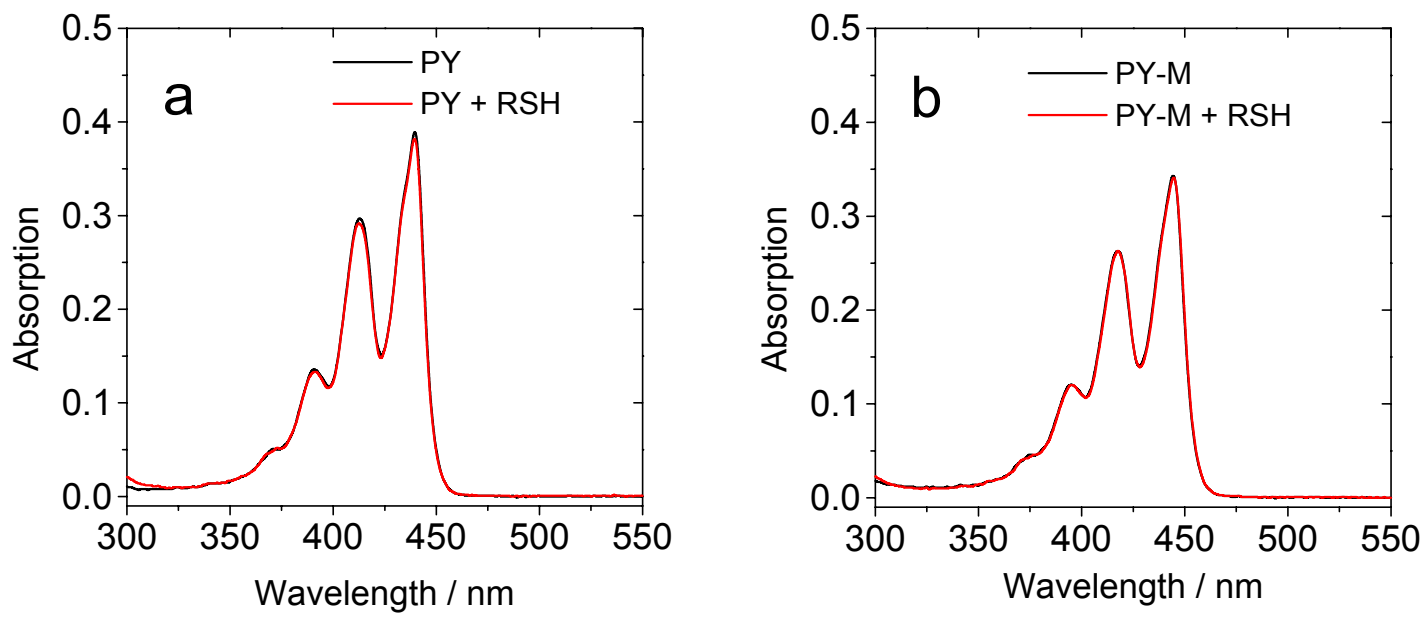

Figure S13. UV-visible absorption spectra of (a) Py and Py +200 equiv. RSH. (b) Py-M and $\mathbf{P y}-\mathbf{M}+200$ equiv. RSH. $\mathbf{c}=1.0 \times 10^{-5} \mathrm{M}$ in DMSO, $20^{\circ} \mathrm{C}$. 


\section{Changes in Fluorescence emission spectra with RSH}

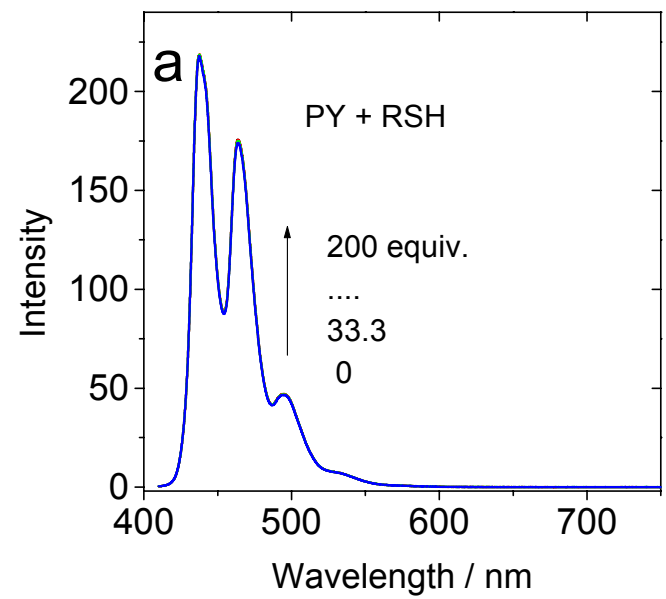

Figure S14. Fluorescence Emission spectra of $\mathbf{P y}$ in the presence of different concentration of 2-mercaptoethanol (RSH) in Methanol $\left(\lambda_{\mathrm{ex}}=406 \mathrm{~nm}\right)$. The absorption in the excitation wavelength is same. $20^{\circ} \mathrm{C}$.
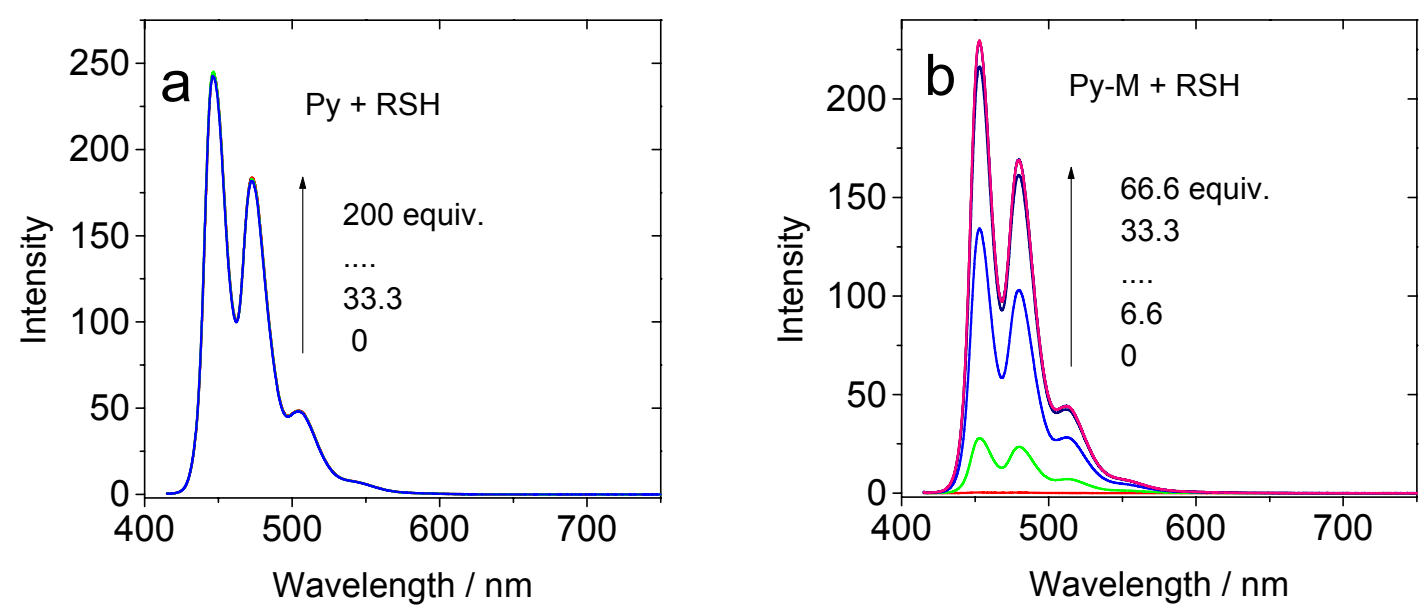

Figure S15. Fluorescence Emission spectra of (a) $\mathbf{P y}$ and (b) $\mathbf{P y}-\mathbf{M}$ in presence of different concentration of 2-mercaptoethanol $(\mathrm{RSH})$ in DMSO $\left(\lambda_{\mathrm{ex}}=412 \mathrm{~nm}\right)$. The absorption in the excitation wavelength is same. $20^{\circ} \mathrm{C}$. 


\section{Structure confirmation by HRMS analysis of Reaction.}

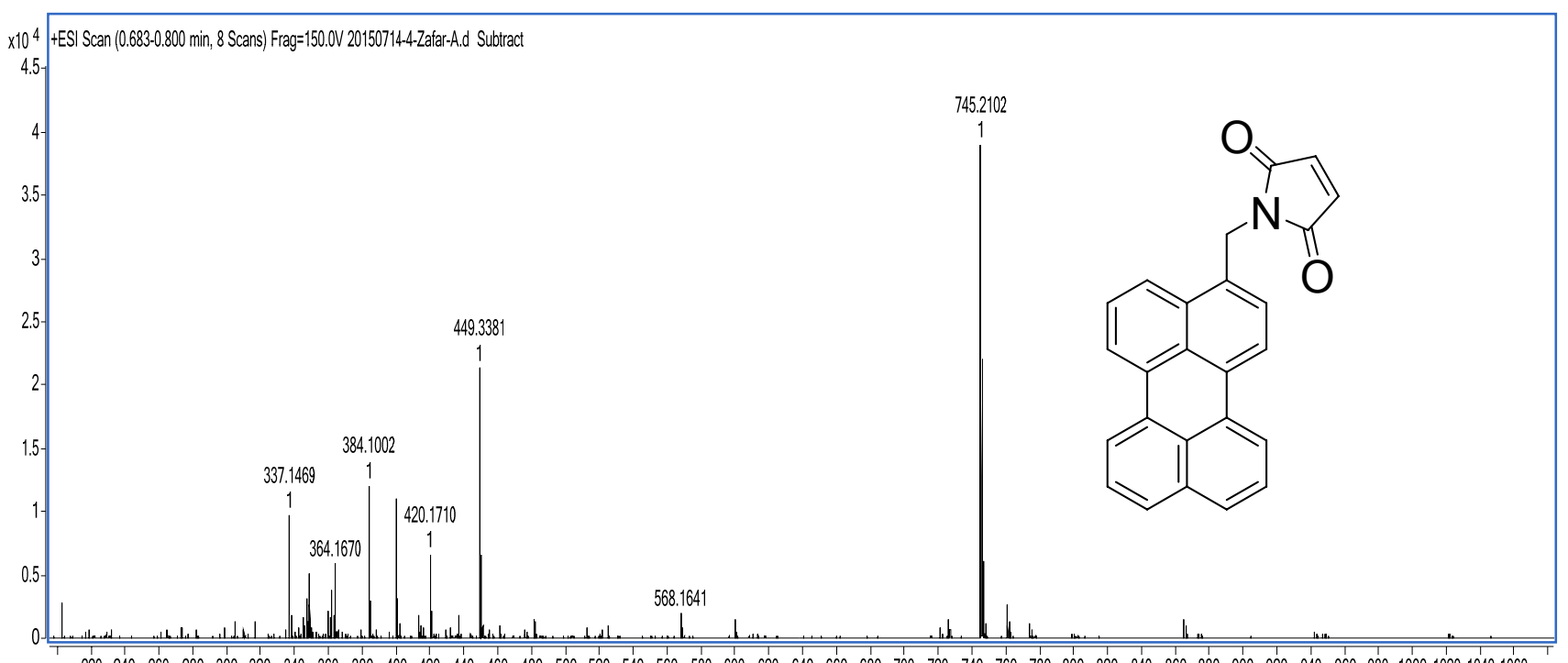

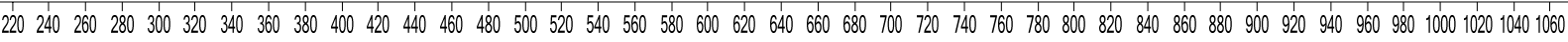
Counts vs. Mass-to-Charge $(\mathrm{m} / \mathrm{z})$

\begin{tabular}{|l|l|l|}
\hline Py-M & Mass calculated & Mass found \\
\hline $\mathbf{M}+\mathbf{N a}^{+}$ & 384.1003 & 384.1002 \\
\hline $\mathbf{2 M}+\mathbf{N a}^{+}$ & 754.2106 & 754.2102 \\
\hline
\end{tabular}

Figure S16. TOF MS ESI Scan of compound Py-M only in MeOH. 


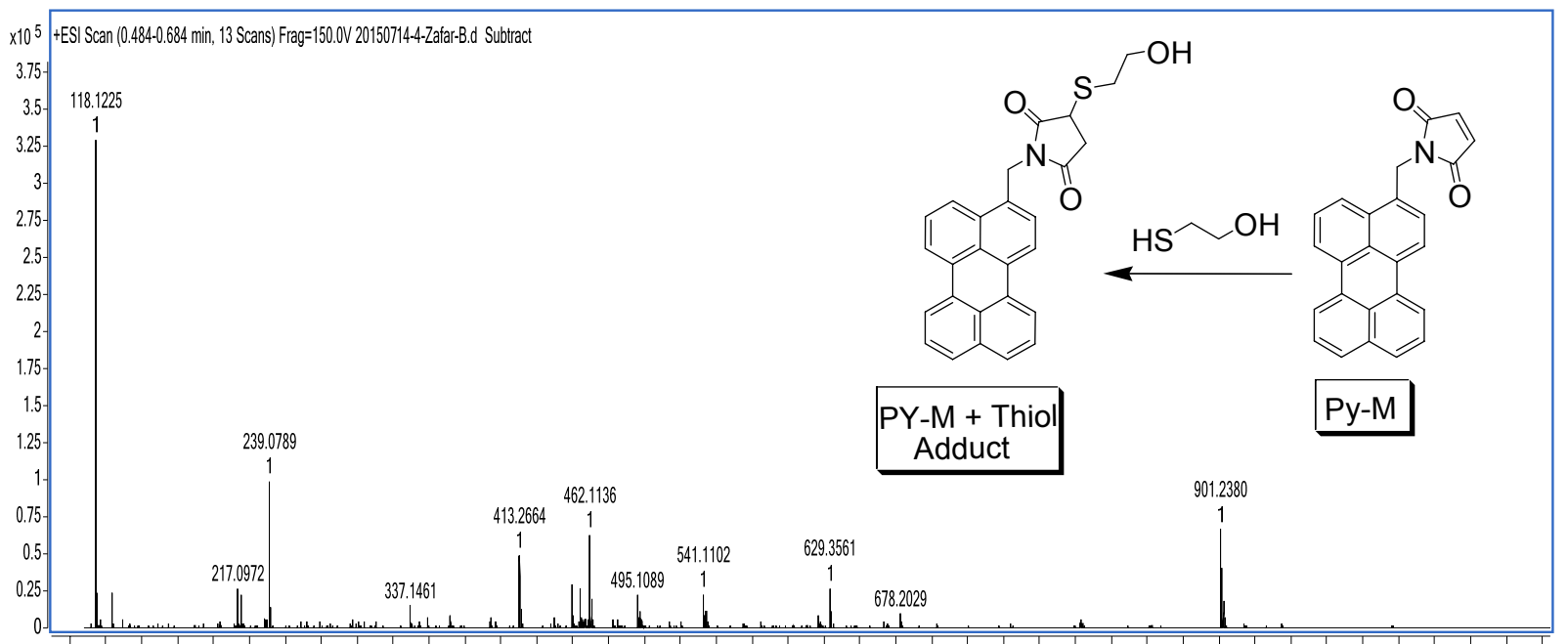

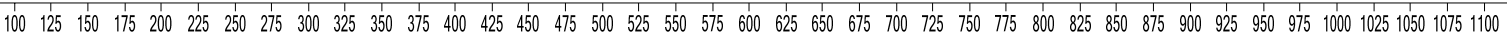
Counts vs. Mass-to-Charge $(\mathrm{m} / \mathrm{z})$

\begin{tabular}{|c|c|l|}
\hline Py-M + RSH & $\begin{array}{c}\text { Mass } \\
\text { calculated }\end{array}$ & Mass found \\
\hline $\mathbf{M}+\mathbf{N a}^{+}$ & 462.1142 & 462.1136 \\
\hline $\mathbf{2 M}+\mathbf{N a}^{+}$ & 901.2384 & 901.2380 \\
\hline
\end{tabular}

Figure S17. TOF MS ESI Scan of compound Py-M + Thiol Reaction mix in $\mathrm{MeOH}$. 


\section{Changes in Fluorescence life time with RSH.}
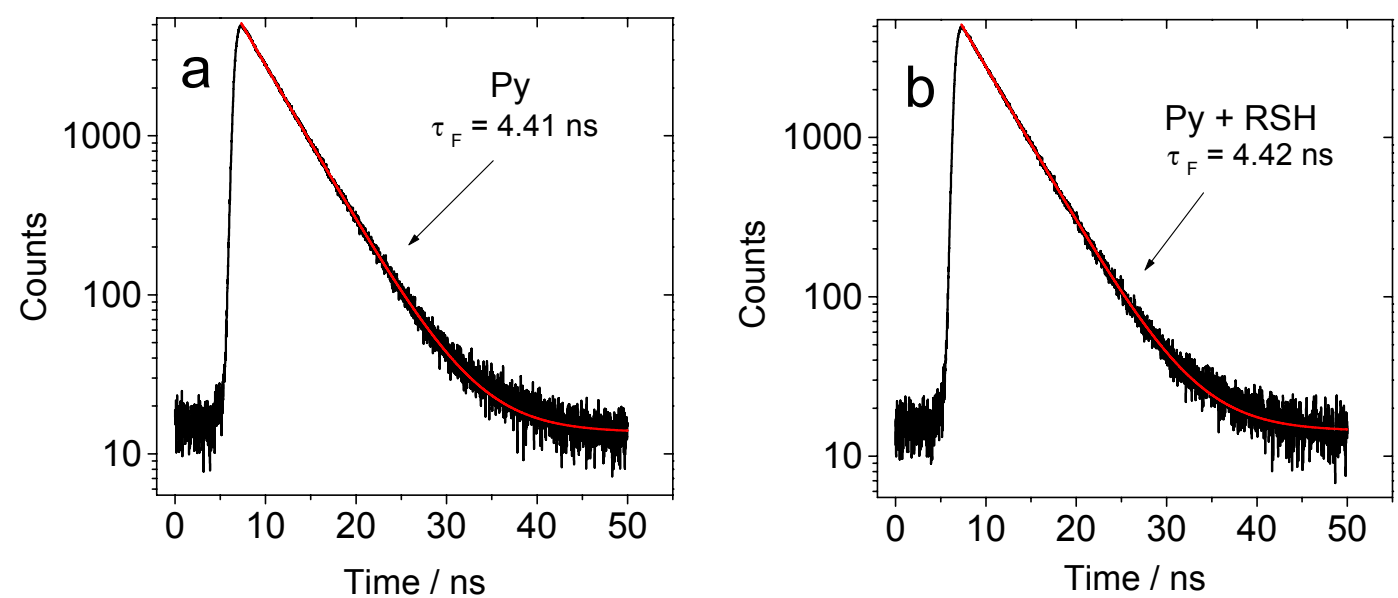

Figure S18. Decay traces of Fluorescence life time of (a) Py (b) Py +200 equiv. 2-mercaptoethanol (RSH). Excited with picoseconds pulsed $405 \mathrm{~nm}$ laser; the decay of emission was monitored at $437 \mathrm{~nm}$. In deaerated Methanol; $c=1.0 \times 10^{-5}, 20^{\circ} \mathrm{C}$. 
7. Switching of TTA Upconversion with RSH.

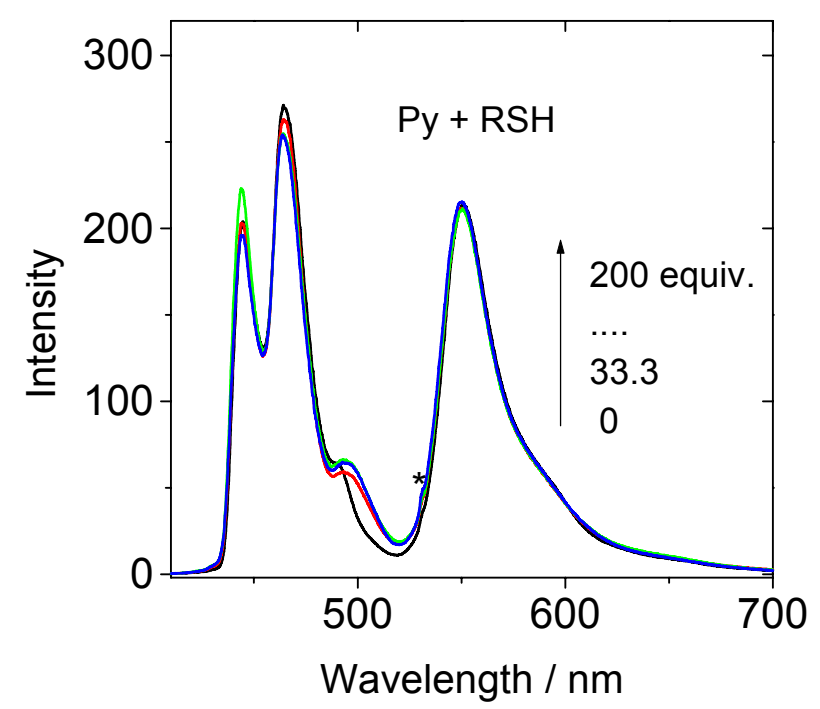

Figure S19. Effect upon upconverted fluorescence emission of perylene $\left(C=7 \times 10^{-5} \mathrm{M}\right)$ with different concentration of RSH ( $c=0.1 \mathrm{M}$ ) in Methanol using B-1 as a photosensitizer, $C$ $=1.0 \times 10^{-5} \mathrm{M}$. Upconversion was performed upon excitation with a $532 \mathrm{~nm}$ continuous laser (power density is $24.5 \mathrm{~mW} \mathrm{~cm}^{-2}$; asterisk is the scattered laser). $20^{\circ} \mathrm{C}$

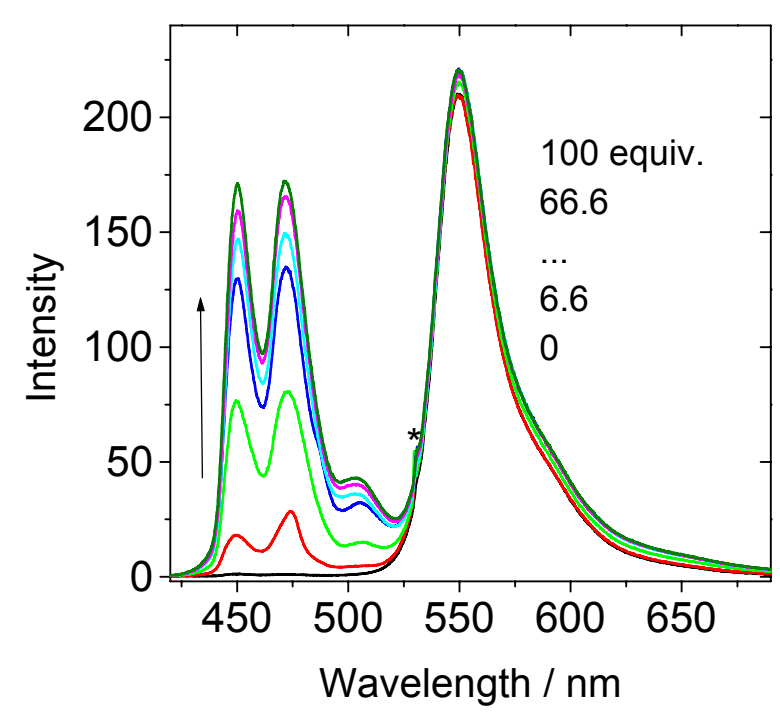

Figure S20. RSH activated upconversion fluorescence emission of Py-M using B-1 as a photosensitizer. Upconversion was performed upon excitation with a $532 \mathrm{~nm}$ continuous laser (power density is $24.5 \mathrm{~mW} \mathrm{~cm}^{-2}$; asterisk is the scattered laser): [B-1] $=1.0 \times 10^{-5} \mathrm{M}$, $[\mathbf{P y}-\mathbf{M}]=7.0 \times 10^{-5} \mathrm{M}$, and $[\mathrm{RSH}]=0.1 \mathrm{M}$ in deaerated Methanol, $20^{\circ} \mathrm{C}$. 


\section{Reaction kinetics of Py-M with thiol.}

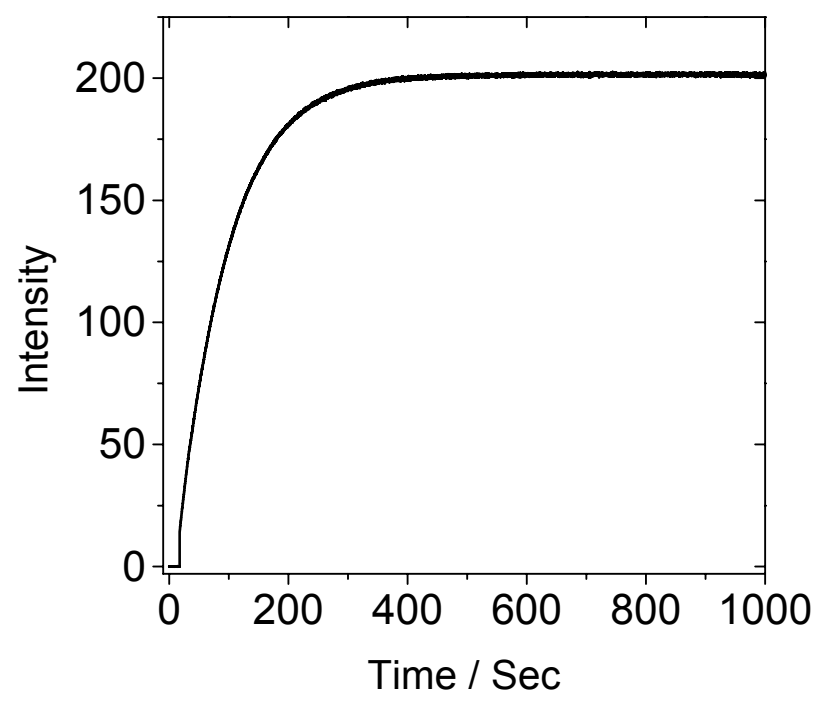

Figure S21. Reaction kinetics of Py-M + 200 equiv. 2-mercaptoethanol (RSH) in methanol; $c[\mathbf{P y}-\mathbf{M}]=1.0 \times 10^{-5} \mathrm{M}, 20^{\circ} \mathrm{C}$. 


\section{Calculation of charge transfer quantum yield $\left(\Phi_{\mathrm{CT}}\right)$.}

The charge transfer quantum yield $\left(\Phi_{\mathrm{CT}}\right)$ was calculated by using equation 2 . It is based on Fluorescence life time data.

$$
\phi_{C S}=\left[\left(1 / \tau_{f}\right)_{\text {dyad }}-\left(1 / \tau_{f}\right)_{\text {ref }}\right] /\left(1 / \tau_{f}\right)_{\text {dyad }}
$$

Where

$\phi_{C S}=$ Charge transfer Quantum yield

$\left(\tau_{f}\right)_{\text {dyad }}=$ short life time in biexponential decay curve of fluorescence life time

$\left(\tau_{f}\right)_{\text {ref }}=$ long life time in biexponential decay curve of fluorescence life time

For Py-M in methanol, $\left(\tau_{f}\right)_{d y a d}=0.46 \mathrm{~ns}$

$$
\begin{aligned}
& \qquad\left(\tau_{f}\right)_{\text {ref }}=4.27 \mathrm{~ns} \\
& \phi_{C S}=[(1 / 0.46)-(1 / 4.27)] /(1 / 0.46) \\
& =0.89 \\
& =89 \%
\end{aligned}
$$


10. Nanosecond Time-resolved Absorption Spectra.
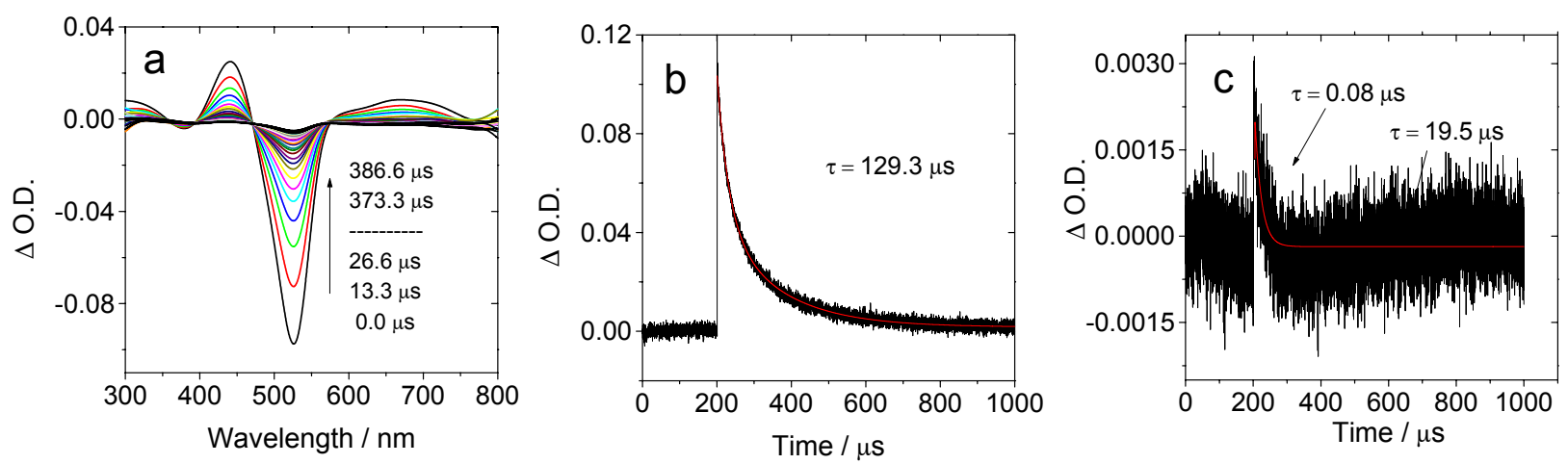

Figure S22. (a) Nanosecond transient absorption spectra of B-1. (b) Decay curve of B-1 at $520 \mathrm{~nm}$ and (c) Decay curve of B-1 at $470 \mathrm{~nm}$. Excited with $532 \mathrm{~nm}$ pulsed laser. Concentration of B-1 $=1.0 \times 10^{-5} \mathrm{M}$, in deaerated Methanol, $20^{\circ} \mathrm{C}$. 


\section{Electrochemistry.}

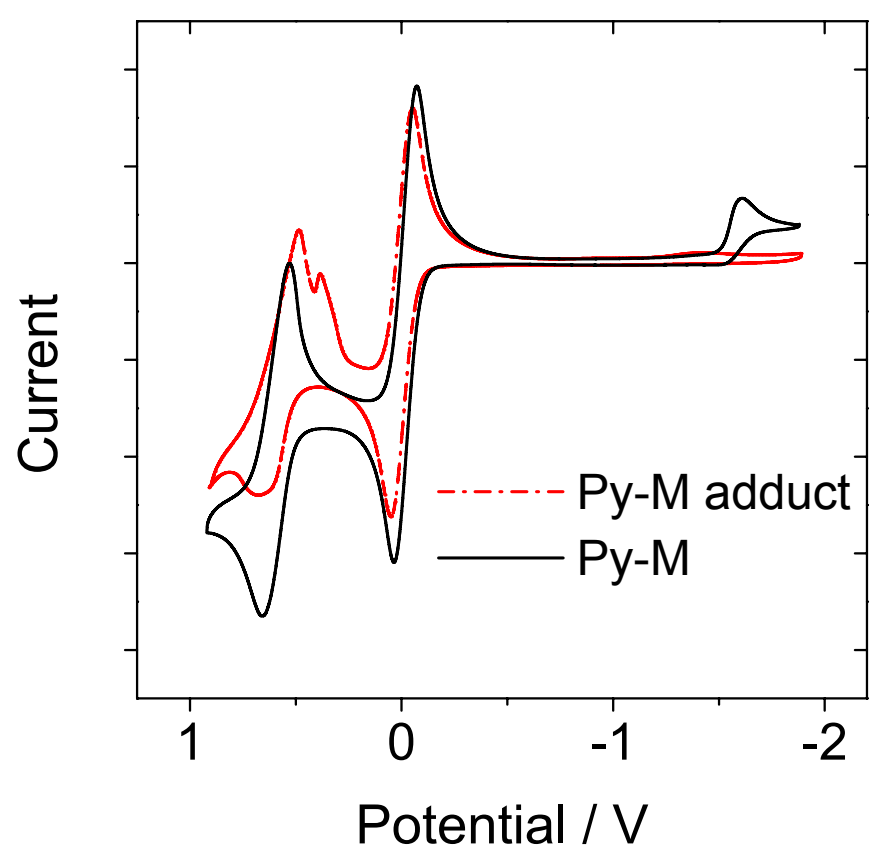

Figure S23. Cyclic voltammogram of the compounds Py-M and Py-M-adduct (1 $\mathrm{mM}$ ). Ferrocene $(\mathrm{Fc})$ was used as internal reference. In deaerated $\mathrm{CH}_{2} \mathrm{Cl}_{2}$ solutions, $0.10 \mathrm{M}$ $\mathrm{Bu}_{4} \mathrm{NPF}_{6}$ as supporting electrolyte, $\mathrm{Ag} / \mathrm{AgNO}_{3}$ reference electrode. Scan rates: $50 \mathrm{mV} / \mathrm{s}$. 20 ${ }^{\circ} \mathrm{C}$. 


\section{Emission titration curves of Py-M with Thiol.}

2-mercaptoethanol was added in the solution of Py-M in methanol, shaked it one time and measured the emission. The emission intensity of Py-M increases with increasing the concentration of 2-mercaptoethanol and become maximum at concentration of $2 \mathrm{mmol}$ (200 equivalent of concentration of Py-M).
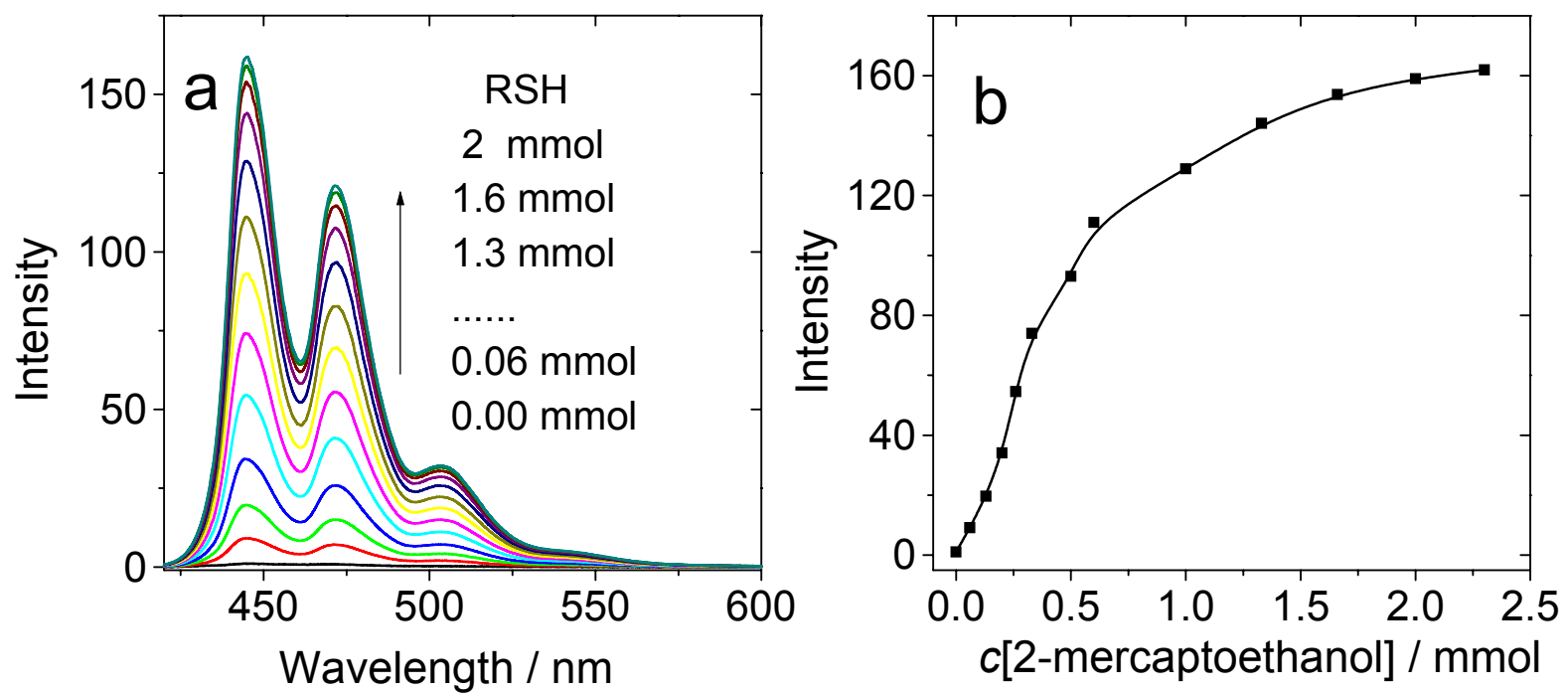

Figure S24. (a) Fluorescence emission of Py-M in the presence of 2-mercaptoethanol ( $\left(\boldsymbol{\lambda}_{\text {ex }}\right.$ $=406 \mathrm{~nm}$ ). $\mathrm{C}=1.0 \times 10^{-5} \mathrm{M}$ in MeOH. $20^{\circ} \mathrm{C}$. (b) Kinetic emission titration curve of Py-M with 2-mercaptoethanol. 